\title{
PEMANFAATAN MEDIA SOSIAL FACEBOOK SEBAGAI MEDIA DAKWAH DALAM MASYARAKAT VIRTUAL
}

\author{
Zulfikar Ghazali \\ Institut Agama Islam Sultan Muhammad Syafiuddin Sambas \\ zulfikarghazali89@gmail.com
}

\begin{abstract}
Abstrak
Peningkatan pengguna internet serta kemajuan teknologi informasi, menyebabkan perubahan terhadap cara berdakwah. Kemudahan untuk. menemui jaringan internet merupakan suatu kelebihan yang dapat menjadikan internet sebagai media atau sebuah sarana alternatif dalam berdakwah. Koneksi atau jaringan internet dapat dijumpai di beberapa tempat seperti warnet, restoran atau caffe yang menyediakan layanan internet menggunakan jaringan wifi, serta layanan internet yang diberikan oleh provider-provider telekomunikasi yang semakin hari semakin berkembang. Selain itu perlu diketahui, kegiatan dakwah islam tidak mesti barus selalu diadakan pada lingkup majelis ta'lim yang berisi ceramah, tausiyah maupun nasihat tentang ilmu keagamaan baik membahas tentang ilmu syari'at Islam, tafsir, taubid, dan lain-lainnya. Tetapi dengan adanya perkembangan teknologi komunikasi dakwah Islam dapat dilakukan dengan cara yang berbeda, salah satunya menggunakan media sosial facebook. Media sosial ini sangat efektif digunakan untuk menyampaikan pesan dakwah, di karenakan banyakny a pengguna dari aplikasi media sosial facebook ini. Kemudahan dalam fasilitas yang disediakan oleb media sosial facebook menjadi kelebihan tersendiri bagi masyarakat virtual khususnya bagi juru dakwah atau para da'i dalam menyampaikan atau membagikan informasi dakwah Islam, berdikusi dan menyambung tali silaturrabim kepada pengguna facebook lainnya.
\end{abstract}

Kata Kunci: Media Dakwah, Media Dakwah Facebook, Pemanfaatan Media Sosial, Dakwah dalam Masyarakat Virtual

\section{Pendahuluan}

Dewasa ini perkembangan teknologi informasi berkembang dengan sangat pesat, khususnya dalam sarana dakwah. Hal ini Berawal dari komputer yang digunakan untuk pribadi berubah dan berkembang menjadi jaringan yang lebih luas, tidak saja untuk jaringan lokal tapi sudah menjadi jaringan komputer global dunia yang di kenal dengan internet. Internet adalah sistem global dari seluruh jaringan komputer yang saling terhubung menggunakan standar Internet Protocol Suite (TCP/IP) untuk melayani miliaran pengguna diseluruh dunia ${ }^{1}$. Kemajuan teknologi informasi dan pemanfaatan terus meningkat dari waktu ke waktu, yang mana hal ini menyebabkan banyaknya masyarakat virtual khususnya juru dakwah atau para da'i menjadikan teknologi informasi sebagai sarana dakwah karena dengan internet mereka dapat menjangkau seluruh umat Islam yang ada di dunia, tanpa harus secara langsung bertemu dengan mereka.

Masyarakat virtual adalah sebuah kehidupan masyarakat manusia yang tidak dapat secara langsung diinderakan melalui penginderaan manusia, namun dapat dirasakan dan disaksikan sebagai sebuah realitas. Kehidupan semacam ini tentu saja bukanlah kehidupan akhirat manusia, namun merupakan sisi lain kehidupan "masyarakat nyata" yang seperti kita ketahui selama ini. Di mana "masyarakat nyata" lebih menekankan pada jalinan kehidupan sosial manusia yang berbasis dan dibangun melalui penginderaan secara langsung ${ }^{2}$. Dalam masyarakat virtual, mendengar ceramah,

\footnotetext{
1 "Definition of Internet", dalam http://www.definitions.ws/95663/internet, diakses tanggal 8 Februari 2017

${ }^{2}$ Rino Setyadi, “Komunikasi Virtual: Sebuah Keniscayaan Masyarakat Teknologi”, dalam http://komunikasi.us/index.php/course/4899-komunitas-virtual-sebuah-keniscayaan-masyarakat-teknologi, diakses tanggal 8 Februari 2017
} 
tausiyah, atau dakwah dari ulama-ulama yang ada baik di dalam negeri maupun diluar negeri, serta mencari informasi keagamaan khususnya yang berhubungan dengan dakwah, tidak perlu membutuhkan modal yang banyak. Karena saat ini sudah sangat banyak sarana-sarana penyampai dakwah yang menggunakan media internet. Penggunaan sarana teknologi informasi sebagai media dakwah memudahkan masyarakat untuk mencari informasi tentang keagamaan baik itu berupa video ceramah, maupun tulisan dengan media internet yang menggunakan web browser sebagai aplikasi penghubungnya. Adapun penggunaan internet sebagai sarana dakwah dapat dilakukan dengan memanfaatkan media sosial, salah satunya adalah facebook. Dakwah melalui media sosial facebook dipandang cukup efektif, dikarenakan aplikasi ini dapat diakses dimana saja dengan catatan harus terkoneksi ke jaringan internet. Selain itu pertumbuhan penggunaan facebook yang cukup signifikan, membuat media sosial facebook menjadi sangat cukup efektif untuk digunakan sebagai sarana dakwah Islam.

\section{Statistik Pengguna Internet di Indonesia}

Berdasarkan pernyataan Kementerian Komunikasi dan Informatika (Kemenkominfo) menggungkapkan bahwa pengguna internet di Indonesia saat ini mencapai 63 juta orang. Dari angka tersebut, 95 persennya menggunakan internet untuk mengakses jejaring sosial. Direktur Pelayanan Informasi Internasional Ditjen Informasi dan Komunikasi Publik (IKP), Selamatta Sembiring mengatakan, situs jejaring sosial yang paling banyak diakses adalah Facebook dan Twitter. Indonesia menempati peringkat 4 pengguna Facebook terbesar setelah USA, Brazil, dan India. Selain itu menurut data dari Webershandwick, perusahaan public relations dan pemberi layanan jasa komunikasi, untuk wilayah Indonesia ada sekitar 65 juta pengguna Facebook aktif. Sebanyak 33 juta pengguna aktif per harinya, 55 juta pengguna aktif yang memakai perangkat mobile dalam pengaksesannya per bulan dan sekitar 28 juta pengguna aktif yang memakai perangkat mobile per harinya ${ }^{3}$.

Asosiasi Penyelenggara Jasa Internet Indonesia (APJII) juga telah membagi pengguna internet dilihat dari beberapa aspek yaitu ${ }^{4}$ :

a. Jenis Kelamin

Survey tahun 2014 menunjukkan bahwa pengguna internet yang berjenis kelamin perempuan lebih banyak dari pada pengguna internet yang berjenis kelamin laki-laki. Mayoritas dari pengguna internet ini tinggal di daerah urban. Adapun untuk perempuan berjumlah $51 \%$ dan laki-laki berjumlah $49 \%$.

b. Usia

Berdasarkan usia pengguna, mayoritas pengguna internet di Indonesia berusia 18-25 tahun, yaitu sebesar hampir setengah dari total jumlah pengguna internet di Indonesia yaitu 49\%, untuk usia 26-35 tahun berjumlah 33,8\%, untuk usia 36-45 tahun berjumlah 14,6\%, untuk usia 46-55 tahun berjumlah 2,4\% dan untuk usia 56-65 tahun berjumlah $0,2 \%$

c. Pendidikan

Berdasarkan pendidikan, pengguna internet di Indonesia paling banyak yang telah menamatkan pendidikannya di tingkat SMU sederajat yaitu berjumlah $64,7 \%$, Sarjana/S1 berjumlah 16,9\%, SMP sederajat berjumlah 9,7\%, Akademi/D1/D2/D3/D4/Vokasi berjumlah 6,8\%, SD sederajat berjumlah 1,2\%, dan Pasca Sarjana/S2/S3 berjumlah 0,4\%

d. Aktivitas

Berdasarkan aktivitas, mayoritas pengguna internet di Indonesia merupakan pekerja dan

3 “Kominfo : Pengguna Internet di Indonesia 63 Juta Orang”, dalam https://goo.gl/1NDYpu, diakses tanggal 8 Februari 2017

${ }^{4}$ Asosiasi Penyelenggara Jasa Internet Indonesia (APJII), Profil Pengguna Internet Indonesia (Penerbit: Asosiasi Penyelenggara Jasa Internet Indonesia, 2015), hlm. 10-17 
wiraswasta yang berjumlah 55\%, mahasiswa sebanyak 18\%, ibu rumah tangga sebanyak 16\%, tidak bekerja sebanyak $6 \%$, dan pelajar SD/SMP/SMA sederajat sebanyak $5 \%$.

e. Pekerjaan

Berdasarkan pekerjaan, mayoritas pengguna internet di Indonesia merupakan karyawan yang berjumlah $65 \%$ pengguna, wirausaha sebanyak $27 \%$, pekerja diluar sektor formal dan informal sebanyak $5 \%$, dan pekerja informal sebanyak 3\%. Sedangkan untuk sektor pekerjaan, mayoritas internet digunakan untuk perdagangan sebesar 31,5\%, jasa sebesar 26,1\%, pendidikan sebesar $8,3 \%$, pemerintahan sebesar 7,0\%, keuangan/perbankan sebesar 5,6\%, otomotif sebesar 3,3\%, konsultan sebesar 3,2\%, manufaktur sebesar 3,2\%, properti sebesar 1,7\%, kesehatan sebesar 1,7\%, hiburan sebesar 1,3\%, perhotelan/restoran/kuliner sebesar 1,0\%, dan agro perkebunan/pertanian sebesar $1,0 \%$

f. Internet Dalam Keluarga

Sebagian besar pengguna internet Indonesia tinggal bersama keluarga batih sebanyak 93\%. Keluarga batih adalah bentuk keluarga yang terdiri dari ayah (suami), ibu (istri), dan anak-anak, keluarga luas sebanyak 10\% dan lainnya sebanyak 6\%. Selain itu mayoritas pengguna internet di Indonesia tinggal di rumah milik orang tua yaitu sebesar 52,6\%, rumah sendiri sebesar 29,8\%, kontrakan sebesar $12,2 \%$, kos/asrama sebesar 4\%, keluarga sebesar $0,7 \%$, lainnya sebesar $0,6 \%$, dan rusun $0,2 \%$

Dari data statisitik pengguna Internet di Indonesia dan data jumlah pengguna Facebook yang telah dijelaskan di latar belakang, dapat disimpulkan bahwa pengguna internet dan aplikasi Facebook di Indonesia memiliki peningkatan yang sangat signifikan.

\section{Penggunaan Internet sebagai Media Dakwah}

Dengan adanya peningkatan pengguna internet serta kemajuan teknologi informasi, menyebabkan perubahan terhadap cara berdakwah. Saat ini para da'i atau juru dakwah mulai memanfaatkan kemajuan teknologi informasi dalam penyampaian dakwahnya. Dengan penggunaan teknologi informasi, kegiatan dakwah bisa dilakukan lebih insentif dan menjangkau jaringan yang lebih luas. Berdasarkan pernyataan Kemkominfo, 95 persen dari 63 juta penduduk Indonesia menggunakan internet untuk mengakses jejaring sosial. Oleh karen itu penggunaan internet sebagai media dakwah bisa menjadi salah satu alternatif yang efektif dalam melakukan dakwah Islam.

\section{Pengertian Dakwah}

Dakwah secara etimologis berasal dari bahasa Arab da'a-yad'u yang berarti memanggil atau menyeru, mengajak atau menngundang. Secara harfiyah dakwah merupakan mashdar dari fi'il (kata kerja) da'a dengan arti ajakan, seruan, undangan, dan panggilan ${ }^{5}$. Warson Munawir menyebutkan bahwa dakwah berarti memanggil (to call), mengundang (to invite), mengajak (to summon), menyeru (to propose), mendorong (to urge), dan memohon (to pray) ${ }^{6}$.

Sedangkan dakwah menurut Al-Quran diartikan sebagai perintah menyeru manusia ke jalan Tuhan dengan cara hikmah dan pelajaran yang baik dengan berbagai metode dan pendekatan, seperti ditegaskan Allah dalam Al-Qur'an surat An-Nahl ayat 125 yang artinya:

"Serulah manusia ke jalan Tuhanmu dengan hikmah dan pelajaran yang baik dan bantahlah mereka dengan jalan yang baik pula. Sesungguhnya Tuhanmu mengetahui siapa yang tersesat dari jalanNya dan Dialah yang Jebih mengetahui orang-orang yang mendapat petunjuk ${ }^{7} . "$

${ }^{5}$ Ridho Syahibi, Metodologi Ilmu Dakwah (Kajian Ontologis Dakwah Ikhwan Al Safa), Yogyakarta: Pustaka Pelajar, 2008, hal 42

${ }^{6}$ Amin Samsul Munir, Ilmu Dakwah, Jakarta: Amzah, 2009, hal 1

${ }^{7}$ Departemen Agama, AI-Qur'an dan Terjemahnya, (Jakarta: DepagRI, 1989), hlm. 419. 
Selain itu pada ayat 104 surat Ali lmran juga menjelaskan pengetian dakwah yang mana artinya sebagai berikut:

"Dan hendaklah ada di antara kamu segolongan umat yang menyeru kepada kebajikan, menyuruh kepada yang ma'ruf dan mencegah dari yang mungkar. Mereka itulah orang-orang yang beruntung.",

Jadi berdasarkan dua surah tersebut dapat disimpulkan bahwa dakwah merupakan sebuah seruan atau ajakan menuju Allah yang mana seruan tersebut berisi ajakan amar ma'ruf nahi mungkar yang dilakukan dengan cara-cara yang baik, dan bertujuan agar objek dakwah mencapai keberuntungan baik itu berupa kebahagiaan di dunia maupun di akhirat.

Dalam mencapai tujuan dakwah Islam, diperlukan sebuah konsep strategi dakwah. Strategi dakwah merupakan sebuah kegiatan perencanaan dalam menentukan metode, pesan, dan pilihan media yang akan digunakan dalam penyampaian dakwah. Dalam konteks pilihan media dakwah, terdapat beberapa macam media dakwah. Media dakwah pada dasarnya bisa diartikan sebagai sesuatu yang dapat dipergunakan sebagai alat untuk mencapai tujuan dakwah. Media tersebut antara lain':

a. Lembaga pendidikan formal, yang bisa dijadikan sebagai media dakwah karena seorang pendidik dapat memasukkan ide-ide dakwahnya melalui proses belajar mengajar

b. Lingkungan keluarga, yang merupakan media dakwah yang paling efektif jika objek dakwahnya adalah kerabat keluarga.

c. Peringatan hari-hari besar Islam, yang sering dipakai oleh seorang juru dakwah untuk menyampai-kan misi dakwahnya kepada masyarakat.

d. Organisasi-organisasi Islam, yang dapat dijadikan sebagai media dakwah melalui misi clan kegiatankegiatan mereka

e. Media massa, yang dapat dipakai oleh juru dakwah dalam menyampaikan pesan-pesan dakwahnya, baik media massa elektronik maupun media massa cetak

\section{Pengenalan Facebook}

Facebook, sesuai dengan namanya adalah sebuah "buku muka." Sebuah "buku" yang memuat banyak "muka" para penggunanya dalam foto, gambar. Maupun ilustrasi. Untuk mendukung fungsi penyimpanan foto-foto tersebut, facebook menyediakan fitur album untuk mengelompokkan foto-foto yang memiliki hubungan tertentu yang disesuaikan dengan selera penggunanya ${ }^{10}$.

Facebook merupakan situs jejaring sosial terbesar di dunia saat ini yang menyediakan berbagai aplikasi yang memudahkan pengguna untuk saling berhubungan kepada para pengguna facebook yang lain. Untuk mendaftar atau membuat facebook dapat kita lakukan tanpa ada biaya sedikitpun atau gratis dan dapat anda lakukan dalam beberapa menit saja. Selain itu berdasarkan latar belakang yang telah dikemukakan di atas, untuk saat ini, pengguna Facebook di Indonesia menduduki peringkat ke-3 dari pengguna Facebook di dunia dan memiliki penetrasi pengguna Facebook via mobile phone tertinggi di dunia, yakni mencapai 88,1\% di tahun 2014 dan akan naik menjadi 92,4 persen di tahun 2015.

Facebook awalnya berasal dari nama 'TheFacebook.com', yang merupakan jaringan sosial skala kecil untuk lingkungan sekolah dan kampus. Mark Elliot Zuckerberg adalah sang penemu Facebook pertama kali yang tinggal di kawasan bernama Dobbs Ferry, Westchester County, kota New York. Tetapi pada bulan September 2006 Facebook membuka pendaftaran untuk jejaring umum dengan syarat memiliki email $^{11}$. Sejak itulah jumlah anggota Facebook melesat seperti sekarang ini. Saat ini hampir semua orang

\footnotetext{
${ }^{8}$ Ibid ,hlm 93

${ }^{9}$ Asmuni Syukir, Dasar-dasar Strategi dakwah Islam, (Surabaya: AI-Ikhlas, 1983). him.201

${ }^{10}$ Muhammad Rezky, Facebook vs Friendster, Yogyakarta: Conexxi, 2009, hal 50

${ }^{11}$ Iskandar Abadi, Penemu dan Sejarah Singkat Facebook Pertama Kali, dalam http://www.indoza.com/2014/02/penemu-facebook-dan-sejarah.html, diakses 8 Februari 2017
} 
mengenal facebook dari anak kecil sampai orang tua.

\section{Pemanfaatan Media Sosial Facebook Sebagai Sarana Dakwah}

Facebook merupakan salah satu bentuk media sosial teknologi informasi dan komunikasi. Berdasarkan pernyataan Webershandwick, perusahaan public relations dan pemberi layanan jasa komunikasi, untuk wilayah Indonesia ada sekitar 65 juta pengguna Facebook aktif. Sebanyak 33 juta pengguna aktif per harinya, 55 juta pengguna aktif yang memakai perangkat mobile dalam pengaksesannya per bulan dan sekitar 28 juta pengguna aktif yang memakai perangkat mobile per harinya ${ }^{12}$. Pernyataan ini dapat membuktikan bahwa media sosial facebook merupakan situs jejaring sosial yang paling favorit dikunjungi dibandingkan dengan situs jejaring sosial lain. Hal ini disebabkan pada media sosial facebook memiliki navigasi yang cukup mudah untuk digunakan oleh penggunanya selain itu aplikasi facebook mempunyai desain minimalis tapi kaya akan fitur dan pendukung. Selain itu dengan jumlah pengguna yang banyak serta penggunaan navigasi yang mudah, dapat menjadikan media sosial facebook sebagai pilihan sarana dakwah masa kini. Maka, tak sedikit dari para para juru dakwah atau da'i memanfaatkan aplikasi facebook yang ada sebagai sarana dakwah Islam.

Dengan melihat perkembangan pengguna facebook yang ada saat ini, berdakwah melalui sarana tersebut akan sangat efektif. Efektivitas facebook ini dapat dilihat dari bagaimana facebook dapat menyebar luas di masyarakat, yaitu dengan pertumbuhan $73 \%$ pertahun dari total pengguna facebook di Indonesia ${ }^{13}$. Selain itu Beberapa fitur yang terdapat di aplikasi facebook ini dapat dimanfaatkan bagi juru dakwah atau para da’i sebagai sarana dakwah Islam yang akan menjembatani kemajuan teknologi dan informasi dengan proses dakwah. Hal ini juga bermaksud untuk merubah paradigma masyarakat yang beranggapan bahwa dakwah Islam hanya dapat dilakukan dalam pengajian saja.

Kata media berasal dari bahasa Latin median yang merupkan jamak dari medium, yang berarti perantara. Adapun yang dimaksud media dakwah adalah perantara (sarana) yang digunakan untuk menyampaikan pesan dakwah ${ }^{14}$. Dalam penggunaan media sosial facebook sebagai sarana dakwah terdapat beberapa peranan penting dari media sosial facebook tersebut antara lain:

a. Sebagai Media Informasi

Salah satu kegiatan yang dapat dilakukan oleh juru dakwah atau para da'i dalam menggunakan media sosial facebook sebagai sarana dakwah yaitu memberikan atau men-share informasi baik itu berupa nasihat, ilmu, kata mutiara, ayat Al-Qur'an beserta tafsirnya, video ceramah dan segala sesuatu yang berhubungan dengan dakwah Islam. Dengan adanya informasi yang berisi dengan dakwah Islam diharapkan dapat membuka wawasan atau menambah pengetahuan seseorang dan dengan pengetahuan tersebut timbullah kesadaran terhadap diri sendiri yang akhirnya orang tersebut akan berprilaku sesuai dengan pengetahuan yang dimilikinya.

b. Sebagai Media Diskusi

Semakin banyak informasi dakwah Islam yang dibagikan atau diberikan, diharapkan dapat membuat para penerima informasi untuk saling bertukar pendapat, mengkaji dan mendiskusikan informasi tersebut menggunakan fasilitas yang ada di media sosial facebook seperti kolom komentar yang disediakan disetiap melakukan update status, selain itu terdapat fasilitas fan page dan membuat group. Hal ini bertujuan untuk menciptakan pembelajaran jarak jauh bagi penerima informasi dakwah untuk mendalami atau mempelajari informasi dakwah Islam yang telah didapatkannya.

c. Sebagai Media Silaturrahim

Dengan adanya interaksi antara pemberi informasi dengan penerima informasi, diharapkan

12 "Kominfo : Pengguna Internet di Indonesia 63 Juta Orang", dalam https://goo.gl/1NDYpu, diakses tanggal 8 Februari 2017

${ }^{13}$ Muhammad Rezky, Facebook vs Friend..., hal v

${ }^{14}$ Asmuni Syukir, Dasar-dasar Strategi....., hlm. 17 
dapat membina tali persaudaraan atau silaturrahim yang erat, baik dengan orang yang dikenal maupun yang tidak dikenal. Agar tercipta rasa cinta dan kasih sayang sesama dan menyebabkan terbentuknya tali persaudaraan yang kuat antara satu orang dengan orang yang lainnya.

\section{Penutup}

Perlu diketahui, kegiatan dakwah islam tidak mesti harus selalu diadakan pada lingkup majelis ta'lim yang berisi ceramah, tausiyah maupun nasihat tentang ilmu keagamaan baik membahas tentang ilmu syari'at Islam, tafsir, tauhid, dan lain-lainnya. Tetapi dengan adanya perkembangan teknologi komunikasi dakwah Islam dapat dilakukan dengan cara yang berbeda, salah satunya menggunakan media sosial facebook. Media sosial ini sangat efektif digunakan untuk menyampaikan pesan dakwah, di karenakan banyaknya pengguna dari aplikasi media sosial facebook ini.

Kemudahan dalam fasilitas yang disediakan oleh media sosial facebook menjadi kelebihan tersendiri bagi masyarakat virtual khususnya bagi juru dakwah atau para da’i dalam menyampaikan atau membagikan informasi dakwah Islam, berdikusi dan menyambung tali silaturrahim kepada pengguna facebook lainnya.

\section{Daftar Pustaka}

Abadi, Iskandar Penemu dan Sejarah Singkat Facebook Pertama Kali, dalam http://www.indoza.com/2014/02/penemu-facebook-dan-sejarah.html, diakses 8 Februari 2017

Asosiasi Penyelenggara Jasa Internet Indonesia (APJII), Profil Pengguna Internet Indonesia (Penerbit: Asosiasi Penyelenggara Jasa Internet Indonesia, 2015)

"Definition of Internet", dalam http://www.definitions.ws/95663/internet, diakses tanggal 8 Februari 2017

Departemen Agama, AI-Qur'an dan Terjemahnya, (Jakarta: DepagRI, 1989)

“Kominfo : Pengguna Internet di Indonesia 63 Juta Orang”, dalam https://goo.gl/1NDYpu, diakses tanggal 8 Februari 2017

Rezky, Muhammad. Facebook vs Friendster, Yogyakarta: Conexxi, 2009

Samsul Munir, Amin. Ilmu Dakwah, Jakarta: Amzah, 2009

Setyadi, Rino "Komunikasi Virtual: Sebuah Keniscayaan Masyarakat Teknologi”, dalam http://komunikasi.us/index.php/course/4899-komunitas-virtual-sebuah-keniscayaanmasyarakat-teknologi, diakses tanggal 8 Februari 2017

Syahibi, Ridh., Metodologi Ilmu Dakwah (Kajian Ontologis Dakwah Ikhwan Al Safa), Yogyakarta: Pustaka Pelajar, 2008

Syukir, Asmuni Dasar-dasar Strategi dakwah Islam, Surabaya: AI-Ikhlas, 1983 